\title{
Authorship Practices and Institutional Contexts in Sociology: Elements for a Comparison of the United States and France
}

David Pontille*

chargé de recherche CNRS

pontille@univ-tlse2.fr

\footnotetext{
* I am very grateful to Blandine Roux for her help in the translation of this paper. My thanks are also due to Jérôme Denis, Michel Grossetti, Marie-Pierre Bes, Gerald Murtagh, Jake Bailey and Delphine Burali and two anonymous reviewers for providing very helpful comments and suggestions on earlier versions of the paper.
} 


\begin{abstract}
Studies of scientific authorship have been developing for forty years. This phenomenon is becoming increasingly well-documented. However, most of these studies deal with fields considered in only one national context. This article tries to understand the specific modalities of sociological authorship within two national contexts: the United States and France. The analysis yields an understanding of the logics intimately linking texts and contexts, throwing light upon the way research and authorship practices are partly shaped by their particular institutional and historical context, but also upon the interactions between cognitive content and patterns of publication.
\end{abstract}

\title{
Keywords
}

Authorship - Scientific Publication - International Comparison - Sociology 
Historians and sociologists have shown how the professionalization of modern science has been characterized by the growth of research teams and collaborative work. Scientific collaborative work has provided a wide subject-matter for researchers using publication as an indicator ${ }^{1}$. The increase in coauthorship rates and in the number of authors per article has been widely documented subsequently in a number of fields (Beaver and Rosen 1978, 1979a, 1979b; Endersby 1996; Price 1963; Zuckerman 1965). With regards to sociology, several studies have analyzed changing publication patterns (McCartney 1970; Oromaner 1974, 1975; Patel 1972, 1973; Wilner 1985). These studies brought to light a general trend throughout the 'core' and 'mainstream' journals of the field (American Journal of Sociology, American Sociological Review, Social Problems, Social Forces and Rural Sociology). This trend is characterized by an increase in the number of authors per article, in the use of statistics, and in financial support.

Although the important rise of teamwork in sociology has been well-documented, one can notice the lack of comparative studies. The major part of research focuses only on a single national dimension (especially the United States). Yet, international comparative studies can enhance our knowledge of institutionalized patterns of authorship in one specific field. Such a comparative point of view could draw a particular perspective concerning the relationship between the institutional conditions and politico-economic forces bearing on a discipline: What kind of disciplinary work is getting done? What kinds of texts are being produced? What counts as disciplinary contributions? These questions are involved with the 'authenticity of what is product' (Strauss 1982) and 'the process of establishing and maintaining legitimacy for particular lines of work' in a specific social world (Gerson 1983, 366). Thus, the expectation of authorship practices allows one to address questions both on the analytical status of scientific publication and on the definition of a field (or a scientific social world): the main purpose here consists in revealing particular interrelations between cognitive content, authorship practices and institutional context for one discipline. Previous work has shown that differences in social patterns lead to differences in various characteristics of journal articles (Katz and Martin 1997). However the particular case analyzed here allows us to point out a specific level that is less documented in the literature : the national institutional contexts for one unique discipline.

In this text, authorship is taken as an extended definition (Pontille 2000b). It is conceived as the result of several interactions between (co)authors themselves (Who signs the text? Who is relaying the acknowledgments? What kind of criteria are considered essential in order to be an author?), between authors and their texts (what kind of criteria are involved in writing the text and in the structure of the argument? Is one 'model' of writing predominant?), and between authors and journals or professional associations (Are there recommendations for name-ordering and for the headings of the text?). To address these questions and bring some new elements to this approach, we focus on a classical distinction between two idealtype models: the 'scientific or experimental model' and the 'literary model' (Lepenies 1988). Wolfe $(1990,479)$ defined these idealtypes by considering that the 'experimental model' is generally 'characterized by shorter sentence construction, elliptical phrasing, greater density of jargon and scientific shorthand, multiple authors, tables and algebraic expressions, stylistic conformity, and greater use of the passive voice', while the 'literary model' is characterized 'by more a leisurely development of ideas, more frequent obiter dicta, less

\footnotetext{
1 Collective publication is far from being the only dimension of scientific collaboration. For critical contributions of this assumption, see Edge (1979); Katz and Martin (1997).
} 
consideration of economy of presentation, single authors, idiosyncratic styles, use of firstperson singular, reliance on metaphor, and more complex rhetorical strategies'. This definition allows us to address the topic: what are the interrelations of these models in contemporary sociological research? Which model is most prevalent in research reports particularly in relation to authorship practices? In this sense, authorship is here elaborated as a specific line of inquiring: it constitutes the point of view in revealing some cognitive and institutional elements that shape sociological publication patterns. In this perspective, three facets of authorship will be more specifically analyzed here (see next section): the number of authors, the kinds of contribution, and the narrative structure of text.

When turning towards a macro-sociological level, this text tends, in part, to smooth out individual practices that are more tinged and complex. Two national contexts will be analyzed (the United-States and France) on a particular historical period: from 1960 to 1995. The post World War II period opened with the carrying out of the Marshall Plan and the increasing State role as economic and social agent of planning and decision making processes. This was an uplifting period for sociology that saw a considerable increase in the financing of sociological research. This period was well-documented concerning the institutionalization and the professionalization of social sciences (Turner and Turner 1990 ; Ross 1991). It is here analyzed by articulating two sets of elements. On the one hand, in this period of institutionalization which forced sociology to define its scientific criteria, the reference (positive or negative) to the experimental sciences 'model' was inevitable. On the other hand, the State's regulating role had gone hand in hand with the accumulation of useful and applied knowledge brought by social sciences (Jenkins and Velody 1970). The analysis focuses on this double process, and especially on its variations according to particular characteristics of national contexts. It tries to reveal some logics intimately linking texts and contexts concerning authorship patterns.

\section{Materials and methodologies}

Several investigations were conducted to support the analysis. In order to grasp the role of professional associations and editors in this shaping, a content analysis of the 'instructions to authors' of the selected journals on the period 1960-1995 was carried out. Also, the content of the American Sociological Association' Style guide (ASA 1997) was analyzed. Although this level of investigation is partly instructive, sociologists' practices needed to be questioned too.

Therefore, interviews were conducted with American and French sociologists $(N=30)$ about their authorship practices. Interviews were organized around the account of personal stories of research and publication, name-ordering, the importance of writing, the different tasks undertaken in the research process, the co-authors' characteristics (status, specific role in the study...), the decision making process of a journal. Stories were chosen by sociologists, who generally related more than one case to illustrate different patterns. The time-span of interviews fluctuated between one hour and a half and two hours according to the experience of each sociologist and their degree of trust. All interviews were done at the office of researchers to facilitate access to the publications we spoke about. Interviewees generally told different stories by looking at their curriculum vitae. As a specific form of selfpresentation, the curriculum vitae is instructive both on the institutional and the cognitive biography of a researcher too. Interviews were then supplemented by the accumulation of this kind of document that will be punctually used in the analysis. 
Also a statistical analysis of a sample of articles published between 1960 and 1995 in different journals was elaborated: American Journal of Sociology (AJS) and American Sociological Review (ASR) for American Sociology, and Cahiers Internationaux de sociologie $(C I S)$, Revue Française de Sociologie (RFS) for French sociology. These journals were chosen because (1) they publish articles on wide and different topics, contrary to others, more 'specialized' ones (e.g. Theory and Society, Symbolic Interactionism, Gender and Society), and (2) interviewees explained to us that those journals 'define the profession' - on this point, see also Glenn (1971). Despite the small number of journals considered here, the national adjective (e.g. 'French sociology') is used to refer to the national context. Only articles were kept; editorials, presidential addresses, letters, research notes, commentaries, replies and rejoinders were systematically excluded. For each article $(\mathrm{N}=1029)$, the number of authors was encoded over the period 1960-95. Two other elements of articles from a subsample $(n=373)$ relative to the years 1965,1980 and 1995 were considered. The first element concerns the kinds of contribution. The coding was done on the basis of the material and the methods used in the article. Five categories of text were elaborated according to the cognitive content: 'theoretical analysis' (analytical discussion of a concept, an author or a paradigm), 'fieldwork analysis' (research based on interview and/or observation), 'statistical analysis' (descriptive or analytical), 'mathematical model' (based on firsthand or secondhand analysis of data), 'textual analysis' (research based on content analysis of textual documents). This analytical categorization should not be understood as an intrinsic and exclusive characteristic of texts. An article was coded as part of one of these five categories on the basis of its argumentation. The second element was the narrative structure of texts. The format that has emerged as a stable genre in the experimental sciences (Bazerman 1988 ; Dear 1991), standardized since 1979 (ANSI 1979), was the focus of the study. This format organizes and cuts out the argument into different sections: Introduction, Material and methods, Results And Discussion (IMRAD). But this generic structure is rarely expressed in its "pure" form in sociological articles. Then, the presence or absence of this division between the problem, the methodological proceedings and the presentation of results was coded.

\section{Trends in American and French sociological research}

As regarding authorship, the statistical analysis clearly reveals national differences (table 1). The rate of co-authored articles increases for all journals between 1960 and 1995, but differentially according to national contexts ${ }^{2}$. Co-authored articles in French journals are more important in 1995 than in 1960 (from $0 \%$ to $12.5 \%$ for CIS and from $5.6 \%$ to $33.3 \%$ for RFS). However they represent only one-fifth to one-third of all articles published in those journals. Yet, American journals show a reversal on the period. Articles move from single authorship (26.9\% for AJS and $8.2 \%$ for ASR in 1960) to coauthorship (54.5\% for AJS and $66.7 \%$ for $A S R$ in 1995).

These national differences are also expressed in the number of authors per coauthored articles (table 2). On the one hand, French articles present a low distribution with the majority co-authored by two authors ( $92,9 \%$ for CIS and $75,8 \%$ for RFS). On the other hand, American articles are more widely co-authored by three, four and five authors per article.

\footnotetext{
2 In this period, the rate of co-authored articles is differential according to the journals too, but this point will not be examined in this paper.
} 
The average of authors is 2.37 for American journals (respectively 2.42 for AJS and 2.33 for $A S R$ ), whereas it is 2.19 for French Journals (respectively 2.07 for CIS and 2.24 for RFS).

Thus American sociological articles are different from the French ones at two levels: they are more often co-authored, and the number of authors per article is larger in most of cases.

Table 1. Coauthorship in four sociological journals, 1960-95

\begin{tabular}{|c|c|c|c|c|c|c|c|c|}
\hline \multirow[b]{3}{*}{ Years } & \multicolumn{4}{|c|}{ American Journals } & \multicolumn{4}{|c|}{ French Journals } \\
\hline & \multicolumn{2}{|c|}{ AJS } & \multicolumn{2}{|c|}{$A S R$} & \multicolumn{2}{|c|}{ CIS } & \multicolumn{2}{|c|}{ RFS } \\
\hline & $\%$ & $n$ & $\%$ & $n$ & $\%$ & $n$ & $\%$ & $n$ \\
\hline 1960 & 26.9 & 52 & 8.2 & 49 & 0.0 & 14 & 5.6 & 18 \\
\hline 1965 & 38.9 & 36 & 28.6 & 42 & 0.0 & 27 & 16.7 & 18 \\
\hline 1970 & 20.0 & 50 & 42.9 & 49 & 0.0 & 14 & 23.5 & 17 \\
\hline 1975 & 39.5 & 43 & 46.9 & 49 & 12.5 & 16 & 23.1 & 13 \\
\hline 1980 & 33.3 & 39 & 46.5 & 43 & 16.7 & 18 & 20.0 & 15 \\
\hline 1985 & 48.5 & 33 & 57.8 & 45 & 22.2 & 27 & 20.0 & 20 \\
\hline 1990 & 60.0 & 35 & 35.9 & 64 & 4.0 & 25 & 30.4 & 23 \\
\hline 1995 & 54.5 & 44 & 66.7 & 51 & 12.5 & 16 & 33.3 & 24 \\
\hline
\end{tabular}

Table 2. Number of authors per coauthored article in four sociological journals, 1960-95

\begin{tabular}{|c|c|c|c|c|c|c|c|c|c|c|c|}
\hline \multirow[b]{3}{*}{ Journals } & \multicolumn{8}{|c|}{ Number of authors } & \multirow{2}{*}{\multicolumn{2}{|c|}{ Total }} & \multirow[b]{3}{*}{$\begin{array}{l}\text { Average of } \\
\text { authors }\end{array}$} \\
\hline & \multicolumn{2}{|c|}{2} & \multicolumn{2}{|c|}{3} & \multicolumn{2}{|c|}{4} & \multicolumn{2}{|c|}{5} & & & \\
\hline & $\%$ & $n$ & $\%$ & $n$ & $\%$ & $n$ & $\%$ & $n$ & $\%$ & $n$ & \\
\hline American Journals & & & & & & & & & & & \\
\hline AJS & 67.4 & 87 & 25.6 & 33 & 4.7 & 6 & 2.3 & 3 & 100.0 & 129 & 2.42 \\
\hline$A S R$ & 73.0 & 119 & 21.5 & 35 & 4.9 & 8 & 0.6 & 1 & 100.0 & 163 & 2.33 \\
\hline French Journals & & & & & & & & & & & \\
\hline $\mathrm{CIS}$ & 92.9 & 13 & 7.1 & 1 & 0.0 & 0 & 0.0 & 0 & 100.0 & 14 & 2.07 \\
\hline RFS & 75.8 & 25 & 24.2 & 8 & 0.0 & 0 & 0.0 & 0 & 100.0 & 33 & 2.24 \\
\hline
\end{tabular}

The analysis of the types of contribution reinforces this trend (figure 1). Theoretical and fieldwork contributions were prevalent in the French journals in 1965 and 1980. By 1995 those analyses left room to statistical ones that represent more than one third of published articles (35\%). The same trend is effective for American journals, but it is more pronounced. As several studies have shown (McCartney 1970; Patel 1972, 1973; Wilner 1985), the content of American sociological articles changed from 1895 to 1965: researches using 'qualitative' methods (interviews, participant observation, case study) progressively gave way to researches based on 'quantitative' methods (survey research, mathematical models). Figure 1 shows that this trend is still ongoing in the nineties ${ }^{3}$. Statistical analysis already represents the majority of contribution printed in 1965 and 1980 (50\% and 48.8\%), but they are more numerously published in 1995 (58.9\%). Theoretical analysis remains present, nevertheless it declined through the period: from $25.6 \%$ in 1965 to $17.9 \%$ in 1995 . Both French and American parts of the sample draw a similar trend towards statistical analysis over the period. However American sociological articles are more often based on this kind of evidence.

\footnotetext{
${ }^{3}$ For a more detailed analysis of characteristics of articles published in AJS and ASR between 1950 and 1995, see Pontille (2000a).
} 
Figure 1. Evolution of types of contribution in four sociological journals, 1965-1980-1995

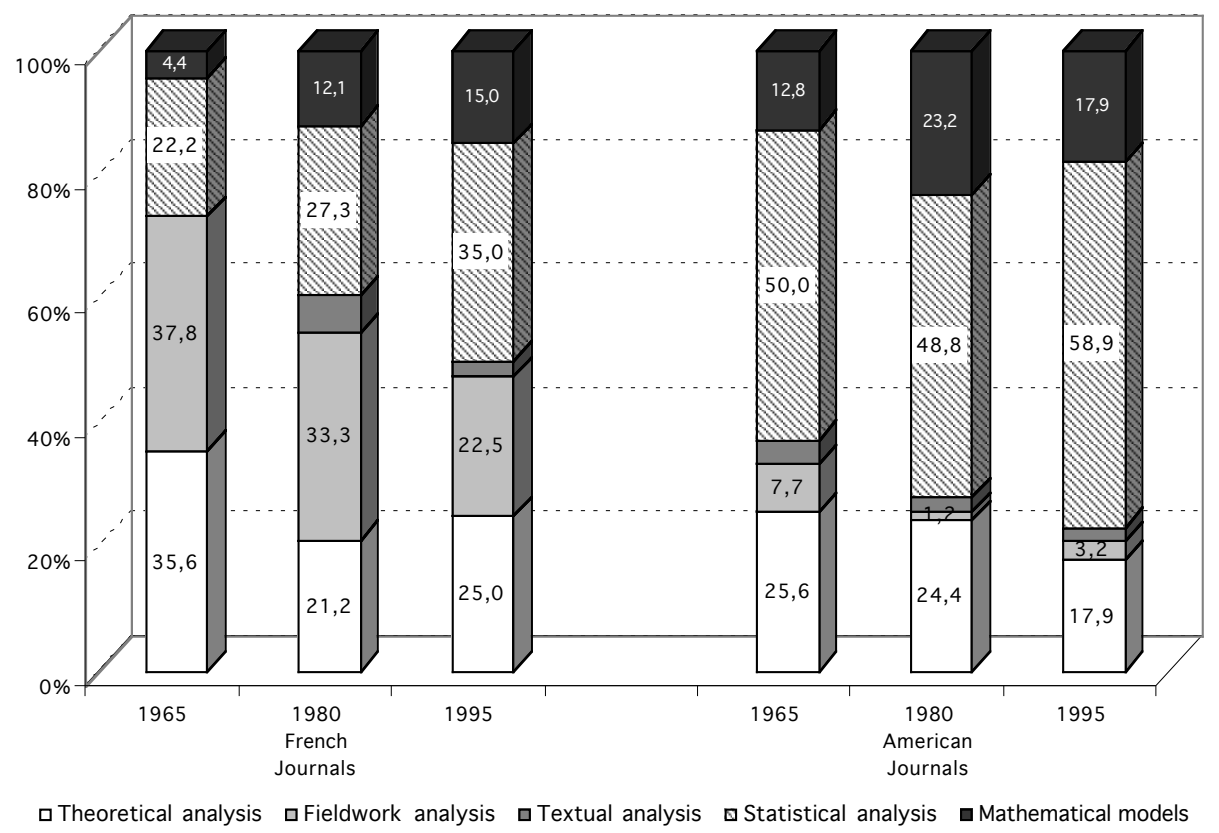

Authorship is also shared differently between the types of articles and national contexts (table 3). The French articles show a trend for single authorship that deals with every kind of contribution, especially theoretical analysis (97\%) and fieldwork analysis (91.9\%). If statistical analysis is well represented in the sample of French contributions (28\%), nevertheless this type of contribution is single authored for a large part (69.7\%). On the other hand, American articles are more differentiated: theoretical analysis, textual analysis and mathematical models are more often single authored (respectively $86 \%, 71.4 \%$ and $63 \%)$, whereas statistical analysis and fieldwork analysis are regularly co-authored $(62.2 \%$ and $60 \%$ ). Thus the increase of coauthorship in American sociological articles is a characteristic of empirical contributions (only $14 \%$ of theoretical analysis is co-authored), and especially the ones that are based on statistical analysis (52.9\%).

Table 3. Coauthored articles and types of contribution, 1965-1980-1995

\begin{tabular}{lccr}
\hline $\begin{array}{c}\text { Types of contribution } \\
\text { American Journals }\end{array}$ & $\begin{array}{c}\text { Coauthored } \\
\text { articles (\%) }\end{array}$ & $\begin{array}{c}\text { Each type of } \\
\text { contribution (\%) }\end{array}$ & Total (n) \\
\hline Theoretical analysis & 14.0 & 22.4 & 57 \\
Fieldwork analysis & 60.0 & 3.9 & 10 \\
Statistical analysis & 62.2 & 52.9 & 135 \\
Mathematical model & 37.0 & 18.0 & 46 \\
Textual analysis & 28.6 & 2.7 & 7 \\
Total & & 100.0 & 255 \\
French Journals & & & \\
Theoretical analysis & 3.0 & 28.0 & 33 \\
Fieldwork analysis & 8.1 & 31.4 & 37 \\
Statistical analysis & 30.3 & 28.0 & 33 \\
Mathematical model & 33.3 & 10.2 & 12 \\
Textual analysis & 33.3 & 2.5 & 3 \\
Total & & 100.0 & 118 \\
\hline
\end{tabular}


Table 4. Presence of the IMRAD according to types of contribution and national contexts, 1965-1980-1995

\begin{tabular}{lrrrr}
\hline & \multicolumn{2}{c}{ American Journals } & \multicolumn{2}{c}{ French Journals } \\
\cline { 2 - 5 } \multicolumn{1}{c}{ IMRAD/type of contribution } & \multicolumn{1}{c}{$\%$} & \multicolumn{1}{c}{$\mathrm{n}$} & \multicolumn{1}{c}{$\%$} & $\mathrm{n}$ \\
\hline Absent/Theoretical analysis & 22.4 & 57 & 28.0 & 33 \\
Absent/Fieldwork analysis & 3.1 & 8 & 31.4 & 37 \\
Absent/Statistical analysis & 11.8 & 30 & 24.6 & 29 \\
Absent/Mathematical model & 10.6 & 27 & 10.2 & 12 \\
Absent/Textual analysis & 2.4 & 6 & 2.5 & 3 \\
Present/Statistical analysis & 41.2 & 105 & 3.4 & 4 \\
Present/Mathematical model & 7.5 & 19 & 0.0 & 0 \\
Present/Fieldwork analysis & 0.8 & 2 & 0.0 & 0 \\
Present/Textual analysis & 0.4 & 1 & 0.0 & 0 \\
Total & 100.0 & 255 & 100.0 & 118 \\
\hline
\end{tabular}

The analysis of the format IMRAD allows underlining the characteristics of articles more precisely. As table 4 shows this narrative structure is differently bound with the kinds of contribution. French articles are ordinary published without this format. Only a small part adopts the generic structure: it is exclusively the case of some statistical analysis (3.4\%). On their part, American articles are divided into two major figures: theoretical analysis without the format IMRAD (22.4\%), and statistical analysis with this narrative structure (41.2\%). The former were more often single authored, whereas the latter were regularly coauthored (table 3). But statistical analysis is not the only kind of contribution published with the format IMRAD in the American part: it is also the case of some articles based on mathematical model (7.5\%).

This statistical analysis reveals that French and American articles are singularly different in their form and their content. On the one hand, most of French articles are single authored whatever kind of contribution they may be. Some articles are co-authored (particularly statistical analyses in RFS), but their argumentation conforms to the format IMRAD in only a very few cases. On the other hand a large part of American articles presents a specific form: they are co-authored, their argument is mostly based on statistical analysis, and the structure of their argumentation corresponds to the format IMRAD. At a formal level these characteristics of text are close to those in the experimental sciences.

How does one grasp these differences? How can we understand them? Are they the artifact of institutional and contextual differences? What can one learn from those differences with regard to the disciplinary work in sociology? To bring some elements to these questions, a sociohistorical analysis of the institutionalization of the sociological discipline in each national context is proposed. The focus concerns the model of research and authorship that is predominant in the processes of institutionalization.

\section{American sociology: the 'scientific' professionalization}

In the United States, the first phase of institutionalization of sociology began in the 1890's through 1940's at the sociology department of the University of Chicago, with the achievement of numerous research efforts (partially financed by the Rockefeller foundation) and the creation of the first journal, the American Journal of Sociology, in 1895. After World 
War II, however the process became widespread in most American universities, together with the mass creation of sociology departments and teaching programs.

In this professionalization movement, reference to the 'model' of the experimental sciences expressed itself at several levels: in the cognitive content and in the mode of organization, as well as in the mode of evaluating productions.

\section{Towards quantification}

From a methodological viewpoint, the postwar period opened with a quantitative turn that contrasted with the sociography of Chicago's first sociologists. For though these sociologists used and integrated official statistics into their socio-anthropological analyses, they used few statistics based on first-hand data 4 . Yet, during this period a movement towards mathematization of social facts, initiated in the thirties, increased significantly. The use of statistical methods was then a guarantor of legitimacy and scientificity for sociology. The work of Camic and Xie (1994) turns out to be particularly relevant in supporting such a statement. Attending to the period between 1890 and 1915 at Columbia University, they examined how four fields (psychology, anthropology, economy, and sociology) incorporated European statistical methods. In this appropriation, they showed how the tools developed by statistics were guarantors of legitimate standards for scientific practices and variously adaptable according to each discipline. They allowed the establishment of scientific legitimacy for each while they specified their singularity (institutional and epistemic boundaries).

Institutionally identified with statistical methods, Columbia University then became a dominant reference against the other competing American universities (notably, John Hopkins, Yale, Cornell, Michigan, and Harvard). By employing scientists specializing in quantitative studies, it thus maintained its advantage in the move towards quantification of social studies that began between 1915 and 1930 (Camic et Xie 1994, 797). This turn towards mathematization of social facts goes on after World War II with P.F. Lazarsfeld, founder of the Bureau of Applied Social Research at Columbia University at the beginning of the forties. The development of survey research was booming, piloted notably by the sociology department of Columbia (under the direction of Lazarsfeld with his research on radio effects financed by the University of Chicago's National Opinion Research Center) and Harvard (with S. Stouffer). Problems relating to the choice of variables, the sampling of population, the formulation of questions were accompanied by the sophistication of the mode of statistical treatment of data: chi-square analysis, factor analysis, latent class analysis, structural equation modeling, and log-linear models (McCartney 1970). This movement towards quantification went on and increased later on at the Universities of Wisconsin and Michigan:

There's a big change that happened in the last twenty years. I mean the Columbia-ChicagoHarvard dominance was followed by a shift towards the very large public universities. They started using large data sets. And then you had the whole Wisconsin school of Robert Hauser,

\footnotetext{
4 The presence of the National Opinion Research Centre within the University of Chicago calls for however nuancing a vision too widely spread in France, that considers that sociologists from Chicago did not use statistical survey methods between 1920 and 1940. This centre financed indeed quantitative opinion research, with some realized in collaboration with some members of the Columbia department. The presence of pro quantitative approach scientists such as W.F. Ogburn or O.D. Duncan at Chicago testify to this orientation. For complementary information on this, see notably Bulmer (1981); Shanas (1945).
} 
David Featherman, and Dudley Duncan, then Michigan. And they gave rise to a very large number of followers, of students... And they tend to try to shift the center of gravity towards large empirical research... (Interview ${ }^{\circ} 21$ )

Thus, sociological research now quantifies the social and tries to chart trends as other sciences do. This cognitive orientation towards quantification brought the sociological mode of production nearer to that of the experimental sciences. But reference to the 'model' of the experimental sciences was not only effective in the adaptation of some of their tools. It was also efficient by the move of persons.

\section{The migration of scientists}

The work of Camic and Xie indirectly shows how in a local context favorable to these evolutions, the initial education (mathematics and physics) of some scientists (Cattell in psychology, Boas in anthropology, Giddings in sociology, and Moore in economics) was important. It was influential in the process of redefinition of the disciplines they investigated, while turning, by means of statistical tools, the quantitative methods into a standard of scientificity for social sciences. And more specifically, Pollak (1979) has shown how Lazarsfeld draws his empirical conception, both quantitative and applied of sociology, from his former education in physics and in mathematics. Other sociologists, deeply involved in the development of mathematical methods in sociology (notably on the modeling side) started their academic education in other disciplines. Graduate schoo/5 academic education encouraged disciplinary 'cross-over': as the sociology department was coupled with that of anthropology at the University of Chicago, other departments were in this period associated with those of economics, of psychology or of political science. The academic education of current sociologists went through a combination of disciplines. Thus, some psychologists and economists went to sociology (as several curriculum vitae of sociologists show). Open to the experimental 'model', these two fields have played a major role in the professionalization of social sciences (Jenkins et Velody 1970). Yet this 'friction' between various fields into social sciences is not the only type of migration operating. Over the 1955-1960 period several public and private institutions also launched for several years research programs requiring disciplinary convergence. For example, the National Mental Health Act promulgated research in medical sociology. Collaborations between doctors and sociologists of Health increased greatly, leading to regular multiple authorship (McCartney 1970 ; Chubin 1975). But other programs went even further. Indeed, the Ford Foundation and the National Science Foundation launched research programs that incited and facilitated 'cross-over' between experimental sciences and social sciences:

In the Mathematical, Physical, and Engineering Sciences Division, there has been established a program in Socio-Physical Sciences. This program includes support of basic research of an interdisciplinarity nature involving convergence of the social sciences and the physical, mathematical, and engineering sciences, including such disciplines as mathematical social science, human geography, economic engineering, and statistical design. (Alpert 1955, 657)

\footnotetext{
${ }^{5}$ For an institutional and historical analysis of Universities and academic systems in several countries, see Ben-David (1991); see also Turner and Turner (1990) for an institutional analysis of American sociology.
} 
This stimulation became effective in several cases ${ }^{6}$. Thus, sociology received an influx of scientists from other fields, such as psychology or economics. Yet, research programs inciting the cross over of experimental sciences and social sciences also led to an infiltration of physicists and of statisticians into sociology, as the following 'education' section ${ }^{7}$ of curriculum vitae clearly show:

\author{
Bachelor of Sciences, MIT \\ Ph.Dissertation, MIT \\ Ph.Dissertation, Princeton University \\ Assistant Professor, University of Chicago \\ ...etc.
Bachelor of Sciences, University of Chicago Master of Sciences, University of Chicago Ph.Dissertation, University of Chicago
Assistant Professor, New York University \\ ...etc.
}

\author{
1950: Physics \\ 1955: Theoretical Physics \\ 1960: Sociology \\ 1959-1963: Sociology
}

1962: Physics

1963: Physics

1969: Physics

1973: Sociology

It is likely that this transfer of people and tools had an impact on both the conception that sociologists had of their discipline and on their working habits. A part of American sociology was deeply reshaped in its research practices, then focused on empirical quantitative research. This recentring of the field is nonetheless more specific to some sociology departments such as Columbia's from the beginning of the century to the fifties, or Michigan's and Wisconsin's from the sixties onwards. However, the disciplines' convergence and their cross over encouraged by research programs are also at the origin of this conception, widely shared by numerous other departments. Furthermore, members of those departments (or educated in those departments) were involved in editing committees of mainstream journals of the field (Wanderer 1966; Yoels 1971, 1974). The intrusion into these journals thus leads to the promotion of contributions essentially oriented towards empirical investigation conducted with statistical methods and/or the mathematical modeling of social facts, despite theoretical publications (Wiley 1979). And in this empirical turn, the narrative structure of articles was also transformed.

\section{The narrative structure}

The mode of writing articles referred to that of the experimental sciences, imposed in the 'instructions to authors' of all journals (with particularities for each). As a matter of fact, the two journals of American sociology considered started this process of formalization and adopted (for empirical contributions) the format IMRAD. This move towards a standardized narrative structure does not operate all at once; it undergoes a progressive standardization in which each section of IMRAD took place. In this 'race for scientificity', psychology has played a major role for the other social sciences in the United States ; it somehow has served as a bridge between social sciences and experimental sciences. The American

\footnotetext{
6 This analysis is based on interviews with American sociologists that either benefited from or witnessed this move. Here is an excerpt of one of these interviews: 'the Ford Foundation had a fellowship program to encourage people to consider a change in field. And so it was a nonthreatening thing, it was just a year, you know it was a bit like taking a year off. So I went to Princeton, where my physics people were. (...) And so I got in there and I was just fascinated. This was in the economics and sociology department. So it was very flexible and a lot of interesting things to do, where I could do what I thought... I hadn't really thought that you could do science in social science’ (Interview n²5).

${ }^{7}$ Only one part of the 'education' section is reported here to avoid any kind of person' identification.
} 
Psychological Association regularly publishes a Publication Manual (first sketch in 1929 and first publication in 1957) dictating the rules to be followed for the proper writing of scientific articles ${ }^{8}$. Reference to this manual was explicitly formulated in some 'instructions to authors' in ASR, whose articles particularly exhibit the trends brought to the fore until now. In the section 'manuscript preparation', one can read:

For clarification of heading formats, abbreviations, table preparation, and so on, or guidance on such issues as using gender-neutral language, refer to the third edition of the Publication Manual of the American Psychological Association. (ASR, 'Notice to contributors', January 1990)

The move towards this 'scientific' form of presentation results in American sociology therefore relying partly on standardized procedures of psychology. However, the American Sociological Association (ASA) plunges in its turn into the race towards normalization of writing. In October 1991, ASA Managing Editors joined together to provide 'some concrete guidance to authors and editors - to specify the kind of writing style and manuscript organization ASA journals expect' (ASA 1997, iii). Though the IMRAD format has not been dealt with in any other particular chapter or paragraph (as opposed to the Publication Manual), it is relatively incorporated into the writing practices, as several articles published in AJS and in ASR testify.

\section{Financial support and visibility}

This period was also characterized by the growth of financial support. Indeed, developed at Columbia under the impulse of P.F. Lazarsfeld at the Bureau, research financed by external and non-academic organizations became little by little acceptable for the academic institution. Greatly copied by the other American universities and exported to most European countries with the impulse of the foundations (especially Ford), this form of research based upon commissioning progressively increased in social sciences (Biderman and Crawford 1970; McCartney 1970, 1971). And this increase was distributed differently according to topics (Simpson 1961). As McCartney (1970) had shown, financial support was more important in sociology of education ( $70 \%$ of articles of this specialty are financed), in sociology of health $(66 \%)$, and in military sociology $(52,2 \%)$ than others specialties of research between 1945 and 1970.

Directed mainly towards development of applied and empirical research in order to enlighten governments in dealing with social problems, funds from these institutions and foundations were not allocated haphazardly (Alpert 1955; McCartney 1971). In this movement of professionalization and of institutionalization of social sciences, it seems that presenting a structured, competent team to obtain reliable results based on quantitative data has been an asset to get financial support from these organizations:

A sociologist who adopts a rigorous scientific stance, complete with the use of statistics, will have more success in obtaining funds to do research and a greater probability of having the results published in the major professional journals. (McCartney 1970, 32-35)

Because the federal funding of universities progressively left room to a mode of financing

8 For an analysis of the codification of scientific writing see Bazerman (1988), and especially the chapter 9: Codifying the Social Scientific Style: the APA Publication Manual as a Behaviorist Rhetoric, 257-277. 
allocated by a diversity of private and public institutions, useful and applied knowledge became a determinant criterion. The scientific image that a team or a scientist can have was then all the more important. Moreover, the period is characterized by the doubling of American Sociological Association (ASA) membership between 1963 and 1971 and the increase of graduates school in sociology between 1967 and 1977 (Turner et Turner 1990). This growth of new sociology Ph.D's found a great competition in the academic market. They had to face a decline of available academic positions, and similarly a greater pressure to publish because the number of publications required for tenure in the U.S. universities rose during the 1970s (Perrucci et al. 1983 ; Clark 1998). This competition led to reinforcement of evaluation criteria in the recruiting commissions and in peer-reviewed journals which flourished between 1968 and 1980 (Hargens 1991). Thus, to have a chance to be selected, the graduates (and in a wider sense any scientist looking for a promotion) had to present curriculum vitae in which must appear 'well-located' publications: as much in the alphabetical order as in the range of peer-reviewed journals. This count of publications warranted a re-examination of authorship patterns: subauthorship (Patel 1973 ; Heffner 1981) became less acceptable in some cases, leaving room for shared authorship collaborations. Usually acknowledged in footnotes for the standing task in the research process, students gained access to authorship and mostly took the second position, after their mentors.

All these elements allow us to grasp certain modifications in sociological practices in the United States. Reference to the experimental sciences 'model' turns research towards an increased use of statistical methods as guarantors of a certain 'scientificity', with repercussions on the article format. In these transformations, sociology is also influenced by scientists from other walks of scientific life (psychology, economics, but also physics and mathematics) importing their knowledge and methods. Simultaneously public and private financial support greatly encourages works with a predominantly useful and applied character. Finally, the massive increase of candidates for a university career facing the available positions tends to reinforce the evaluation criteria and to modify authorship patterns.

Empirical research based on quantitative data enables sociologists to operate more easily than other methods of standardizing concepts and techniques leading to a certain work organization: work can be divided and ranked among different complementary operations. In such division of labor, the article format allows, in some cases, several scholars to write the different parts (introduction, material and methods, results, discussion, conclusion) of the final article 9 . In this context of a new work organization starting under the impulse of a specific content of knowledge (empirical quantitative) and of a specific form of research (financed and commissioned) linked to the new requirement for publications, collaborative team research and coauthorship become a common practice. These contextual elements throw light upon the transformations in the nature and form of texts.

\footnotetext{
9 'l've done co-authorship where one person writes one section, another person writes another section... I did that with the graduate student that I wrote the two papers with. In the first paper we did more of that, but it's just hard to make sure the style flows, and that the paper is consistent. Not just in terms of style, but in terms of focus and theoretical development and that sort of thing. It's hard to make that work' (Interview n¹9).
} 


\section{French sociology: between vocation and professionalization}

The post-war period was one of great institutionalization for French sociology (Pollak 1976 ; Drouard 1982 ; Sainsaulieu 1988 ; Chapoulie 1991 ; Chenu 1998 ; Farrugia 1999)10. As opposed to American sociology, already institutionalized at least at the University of Chicago, French sociology barely existed as an academic discipline prior to the fifties. Though a first foundation was operated by Durkheim and his followers, notably with the founding of Année Sociologique and the obtention of a chair at Bordeaux ${ }^{11}$, it was only after 1945 that French sociology became an autonomous academic discipline. The first sociology laboratory, the Centre d'études sociologiques (CES) and the Cahiers internationaux de sociologie were created in 1946 on the initiative and under the direction of G. Gurvitch. This institutionalization increased during the 1950-1970 period with the growth of financing linked with State research institutions, the creation of the $\mathrm{VI}^{\text {th }}$ section ('sciences économiques et sociales') of the Ecole Pratique des Hautes Etudes (EPHE) in 1948 and of the licence de sociologie in 1958. Added to this, a system of publication also emerged: a collection of books at the Presses Universitaires de France (the Bibliothèque de sociologie contemporaine) in 1950 and several academic journals.

As for the American case, only certain aspects of this institutionalization will be retained here to illustrate the present study: the importance of philosophy, the directions of the CES, and the relation towards financial support.

\section{The importance of philosophy}

In this process of institutionalization, French sociology has been marked by philosophy. This rooting in the humanities is visible on both institutional and cognitive levels. From an institutional standpoint, sociology was dominated by philosophy until 1970 . The absence of an academic curriculum obliged sociologists to defend their Ph.D. in front of committees essentially composed by members of other fields:

Dominated in facultés de lettres by philosophy (and also by history) sociology remained marked by its mother-disciplines: predilection for a literary style, treatment of great 'theoretical' topics, scarcity of empirical researches. (Pollak 1976, 106)

Thus, until the creation of the 'licence' and of the 'doctorat' of sociology in 1958 and 1959, scientists identifying themselves with 'sociology' were evaluated by other disciplines which were academic rivals. This dependence is to a degree still true today: whereas economy is linked up with Facultés de Droit et des Sciences Economiques, sociology is taught in the Facultés de Lettres et des Sciences Humaines: next to philosophy and history.

From a cognitive standpoint, the type of works realized in sociology during this period bore the trace of this literary and philosophical tradition. An interest in grand theory and in 'synthesis' has been its main expression. For though the specialists in 'sociology' who clustered at the CES realized empirical works and investigations,

\footnotetext{
10 To supplement this overview of French sociology, see the special issue of Revue Française de Sociologie (vol. 32-3, 1991, 'Reconstructions de la sociologie française') and of L'Homme et la Société ( ${ }^{\circ} 131,1999$, 'Politiques des sciences sociales').

${ }^{11}$ For a very interesting historical analysis of this first foundation, see Mucchielli (1998).
} 
it is also necessary to insist on the fact that, among university people, and especially the Sorbonne professors, only a very small minority was ready to accept as genuine university work the empirical investigation of contemporary reality. (Chapoulie 1991, 329)

The sociological model of scientificity has been characterized by its ambivalence between this literary and philosophical tradition on the one hand, and the experimental investigation of sciences, on the other hand. However it was on the side of experimental sciences that the ambivalence of the reference has been the most pronounced. It has been the object of several intermediates. Whereas in the United States, psychology has been the bridge between the social sciences and the experimental sciences, in France it has been rather economics that has played this role by mathematizing itself before the other social sciences. The collecting of ciphered information impulsed by the reinforcing of the technical and statistical services of the state then becomes a priority for the construction of the economy (Pollak 1976 ; Drouard 1982).

But to the eyes of the first French sociologists, a second intermediate comes to the fore: American sociology, perceived as unified, became the model to follow in acquiring investigation methods. The borrowings liable to promote the 'scientific' label claimed by the new discipline occured primarily on the methodological side. French sociologists (Bourricaud, Crozier, Mendras, Boudon, Touraine, Tréanton, Stoetzel...) made stays, partially financed by Fulbright scholarships and as part of Marshall Plan productivity missions, in some American universities (Chicago, Harvard, Columbia, Cornell...). There they discovered and learnt research methods (interview, survey, statistics) and some modes of data treatment grounded in original first-hand documentation. These initiation trips were an important step in their learning the job of the sociologist.

At the time, to obtain a grant to attend an American university during a year, that was a real treat. (...) In Chicago I found what I was looking for: a biting worrying to go get a look at things, to plunge my hands in the social dirty grease (...) I learnt my job as I wished to and as you could not learn in Paris at the time. (Mendras 1995, p.43-48)

However, though looking to its American counterpart for the scientificity it has offered, French sociology simultaneously has claimed an identity and an originality which still survives today (Wieviorka 1996). French sociologists then criticized some aspects of American sociology that they otherwise adulated. These sociologists were aware of the weak attention paid to the historical dimension and the absence of explicit theoretical conceptualization which condemned the use of statistics at best to descriptions, at worst to 'quantophrenia'. Besides, in the political context of the period, under the ideological sway of Marxism and the influence of the Communist Party, French sociologists were impressed by the insufficient attention paid to social problems in general, and social classes in particular. This ambivalence in the reference to American sociology is visible in the lines of the discipline's institutionalization, notably in the successive directions of the CES.

\section{CES directors: numbers against letters}

The rebuilding of French sociology partly operated outside the universities. There were indeed only four positions for sociology in 1939, all in facultés de lettres: two at the Sorbonne (occupied by A. Bayet until 1948 and by G. Davy until 1955); one in Bordeaux invested by J. Stoetzel until 1945 (date of his being nominated at the Sorbonne on a social psychology position); and one in Strasbourg occupied by G. Gurvitch from 1935 on. This poor list is completed by the position of the Conservatoire national des arts et métiers 
invested by G. Friedmann in 1946, and the research teams welcomed by the $\mathrm{V}^{\text {th }}$ section of the EPHE, as well as the sociology courses given notably by G. Le Bras, G. Friedmann and J. Stoetzel at the Institut d'études politiques of Paris.

During this period of 'second founding' of French sociology, the creation of the CES in May 1946 in the new CNRS institutional environment, was crucial. Founded by Gurvitch, the centre was under his direction until 1949. The CES's main objective was first to organize conferences aimed at apprentice sociologists. The university members who participated in the CES activities came from various horizons: history, geography, ethnology, literature, and philosophy. It was among this variety that field work and the constitution of the first research teams took place:

Chombart and Maucorps, then America, had convinced us that research had to be undertaken by teams. The first were convinced that, from now on, research in social science would be a collective work. For them, solitary research was not worth it except for literary disciplines; it did not fit social sciences. (Mendras 1995, 56)

However, this form of empirical and collective organisation of work took different shapes under the different directions of CES. For more than ten years, it was Gurvitch himself who imposed himself. The centre's director, he was also director of studies at the $\mathrm{V}^{\text {th }}$ section of the EPHE, and dominated on his own the discipline until the arrival of Friedmann at the CNRS and at the direction of the CES in 1949. Friedmann 'distinguished himself by the dissatisfaction that mere philosophical thought about the working class generates' (Chapoulie 1991, 336). He was therefore one of the rare sociologists of his generation to look upon field work as necessary, and he thus contributed to the introduction in France of American empirical research in sociology of labor. The thematic cutting of research was initiated at his impulse at the CES (Mendras 1995, 57).

However, it was under the direction of Stoetzel that the empirical approach became paramount ${ }^{12}$. His taking of a director position in 1955 was accompanied by a new orientation of sociological discipline. Since he was trained with Lazarsfeld and Gallup at Columbia, he had never ceased to promote quantitative research in sociology:

Time will probably come, for which I am personally waiting with impatient irony (...) when we will see the best sociologists write terrible works of philosophy. Then, sociology will be a science. (...) The more quantitative our sociological knowledge, the more solid and the more scientific our knowledge. This is the reason why statistical analysis has such an increasing role in sociology. New sociology must thus cease to be 'general', 'leave ambitious syntheses' and look for 'extreme specialization'. It must free itself from philosophy, but also from morals and literature, and summon 'the number and the measure'. (Conference by Stoetzel in front of the Société de philosophie de Bordeaux quoted by Farrugia 1999, 24)

Besides the fact that he introduced Anglo-Saxon quantitative empirical methods in academic research, Stoetzel was deeply involved in a pragmatic approach. Funding the Institut français d'opinion publique (IFOP) in 1938, he was also in France the instigator of a research based on contracts. He then contributed in bending sociological research towards an applicable form and expertise. On the academic level, the Revue française de sociologie which he created in 1960 played the role of medium for the diffusion of research works with

\footnotetext{
12 For an analysis of the first research reports of French sociologists in this period, see Chapoulie
} (1991, 352-358). 
a quantitative orientation. Sociology became promoted for its capacity to bring ciphered solutions to accurate social and political questions. It is here conceived as a profession.

However, the influence of philosophy is still active in the sociological rows. Gurvitch and his fellows (Ansart, Balandier, Duvignaud, Lefebvre, etc.) develop a conception in reaction towards this solely empirical and applied trend of sociology. These sociologists do not reject fieldwork altogether. But they are more part of the critical theory. They therefore prevent this sort of sociology from running the risk of losing all critical distance by reducing itself to a research 'technique'. The founding of the Cahiers internationaux de sociologie put in concrete form this will to open up wider by welcoming 'reflection' articles. The use of numbers does not mean it is the intelligible mode, letters are more than necessary to give them meaning. This protection against the scientificity effect provided by the use of statistical methods operates then at different levels. The first level, methodological, is concerned with preventing the blind use of data which can be induced by the quantification of social facts. The second level, political, is directed against American imperialism and its hold on social sciences, notably at the methodological but also financial levels. The third level concerns the place of the sociologist in the state: if Stoetzel's point of view tends to install a professionalization by numbers, Gurvitch and his fellows consider to the contrary that sociology, experienced as a true vocation, must stay close to philosophy while keeping its lettres de noblesse.

Defining itself sometimes as an activity close to empirical application and expertise, and sometimes as a form of generalizing synthesis leaving out any 'external pressure', French sociology is thus marked by a strong ambivalence. This ambivalence lies in the ambiguous relations which French sociology entertains with the social command.

\section{Financial support and authorship practices}

After 1945, the State has incited social sciences to produce useful and applied knowledge in aid of planning decisions. In this institutionalization of the social sciences movement, the role of the Délégation générale à la recherche scientifique et technique (DGRST) was fundamental in setting research contracts and programs (Drouard 1982). Built at the interface of academia and the politico-administrative system, this particular form of policyrelevant research has also been controversial. On the one hand, contractual research has been perceived as an opportunity for institutionalization and professionalization. It has made possible the practice of a recognized sociological occupation by legitimating knowledge produced by sociology. On the other hand, the financial support that the social sciences obtained (in the United States and in Europe) from the American army was vigorously criticized in the political context of this period. The philosophical marks, from which sociology was barely freeing itself, gave rise to a strong reservation: that of becoming 'social engineers' by being instrumentalized by commissioners (Amiot 1986).

This ambivalence is still widely shared today. Until the beginning of the nineties according to Piriou (Piriou 1999), French sociologists have refused any kind of professionalization outside the university setting (Chenu 1998). Such a conception seems yet to leave more and more room for 'practical' sociology, with notably the creation of professional organizations (the Association professionnelle des sociologues created in 1981, and the Association des professionnels en sociologie de l'entreprise founded in 1998). If contractual practices were impulsed at the end of World War II, and they lasted until today, it seems therefore that it has only been during the past ten years that this form of research outside the university 
setting has become, despite Stoetzel's impulsions, considered as legitimately worthy of the sociologist's status in France.

Heir to this historical context of production, French sociology partly keeps some traces of its academic roots. Collective work, punctually developed in the first teams of the CES, and also around some important figures of the period (Crozier at the Centre de sociologie des organisations, Touraine, or Bourdieu at the Centre de sociologie européenne) can easily start. However, the importance of certain institutionalization characteristics of French sociology has marked its modalities of publication. Even when work (especially data collection) is realized partly in collaboration, several criteria remain fundamentally determining for authorship. Writing is ranked high in the hierarchy of various research operations (methodological conception, data collection, analysis...) ${ }^{13}$.

The hierarchical position linked with the responsibility for the project is also vital, relegating students and other research assistants to subauthorship (acknowledgement). Therefore, the call for other competences (statistics and mathematics) is generally not integrated to the publication process: sociologists subcontract statisticians for a part of empirical work seen as depreciating. Then, the definition of sociological practice - as vocation, as occupation, then as profession - seems to echo publication practices. The reluctance to contract research favours a dichotomy between single-authored productions (sometimes produced collectively) of the 'academic sphere' and coauthored research reports dedicated to commissioners.

\section{Authorship practices: between texts and contexts}

From the point of view of international standardization, one can tell that the 'experimental model' will probably become a common horizon for sociological productions. This model has settle a way of producing statements of great detail and reliability among a large variety of fields (Bazerman 1988). But patterns of institutional processes for one discipline are sometimes different. In French and American sociology both the 'intersection processes' and the 'legitimation processes' (Gerson 1983) are involved in singular ways. The differences pointed out here are significant: they illustrate how the institutional contexts shape modalities of production as well as authorship patterns.

If previous work indicated these kinds of interactions, the particular case analyzed here enables pointing out several organizational arrangements. First, the reference to the 'experimental model' turns research towards an increased use of particular methodological tools (statistical analyses) as guarantors of a certain 'scientificity'. Importation of statistical methods and narrative structure of 'experimental model' does the positive assertion of legitimacy for a large part of American sociologists, while it is more ambiguous for French sociologists. Second, the initial education (in mathematics and physics, or in philosophy and literature) of some scientists influences the disciplinary work that is getting done, the

\footnotetext{
13 'Writing is a crucial criterion. If there are two coauthors, I hardly can imagine there would be a big unbalance where writing production is concerned' (Interview $n^{\circ} 5$ ); 'I strongly rely on the rule 'who writes signs his or her name'. And of course, it happened to me to be on research projects where people who did not write, did not put their name. That's obvious. (...) Otherwise... no this is a minimum. After all you don't put your name just for anything, you sign a text. You sign if you write’ (Interview n¹1).
} 
kinds of texts that are being produced, and the work that counts as 'authentic' disciplinary contributions. Third, the 'authenticity of what is product' is involved with the setting of institutional and epistemic boundaries among disciplines. This boundary-work establishes the legitimacy of research problems and of standardized methodological techniques for scientific practices. While intersections of American sociological practices are concerned with statistics, physics and psychology, French ones are more implicated with philosophy, literature and economics. Finally, the institutional conditions and politico-economic forces bearing on a discipline define modes of funding and lines of research programs. If contractual research could be an opportunity to realize academic and applied research, it could be vigorously criticized in particular political context (as in 1960s in France) on the other hand.

These elements show that standards and boundaries of a scientific social world are intrinsically shaped by the relationship between cognitive content and institutional contexts. In the case analyzed here, these contexts include a specific dimension: the national one, that moulds in particular ways the modes of production, presentation and evaluation of sociological researches. The ambivalence between the use of measure to draw trends and the importance of text to give meaning is polarized. American sociological productions are characterized by a decisive quantitative turn that affects a large (but not exclusive) share of contributions. This movement of ordering cognitive content, research and publication practices, associates in a particularly consistent manner the scientific legitimacy of the discipline, practical applications of knowledge and professionalization of its members. French sociology, on the other hand, oscillates in a more pronounced way between practices inherited from a far older academic tradition (philosophy and literature) and the beginning of professionalization through the adoption of the 'experimental model' embodied in part by American sociology. Its institutionalization did not operate in a quantitative turn, but through an ambivalence in which the humanities have a major place. Thus, the polarization of ambivalence according to national contexts throw light upon modes of production of sociological knowledge, at one time closed to the 'experimental' model, at another time closed to the 'literary' model (Lepenies 1988). It yields an understanding of the differences among authorship practices according to national contexts.

Publication, the central communication tool of the scientific activity (diffusion of knowledge, training and peer assessment of scientists), was widely studied from an evaluative perspective (productivity of scientists, laboratories, countries...). By reconsidering its status, this study has attempted to bring to the fore that it is as much an element in the construction of research practices as a structured space for their legibility. As a critical vector for scientific production, publication cristallizes, in a specific way, the particular links woven between the cognitive and institutional aspects of a field. This work hence reveals that the understanding of a field's scientific practices goes necessarily with the analysis of the specific interrelations between its contextual modalities of institutionalization and the characteristics of knowledge it produces.

\section{References}

Alpert, H. 1955. The social sciences and the National Science Foundation: 1945-1955. American Sociological Review 20(6): 653-60.

American, National Standards Institute. 1979. American National Standard for the preparation of scientific papers for written or oral presentation. New York. 
American, Sociological Association. 1997. Style Guide. Washington, DC: American Sociological Association.

Amiot, Michel. 1986. Contre l'Etat les sociologues. Paris: Ecole des hautes études en sciences sociales.

Bazerman, Charles. 1988. Shaping written knowledge: the genre and activity of the experimental article in science. Madison, Wisconsin: The University of Wisconsin Press.

Beaver, Donald and R. Rosen. 1978. Studies in scientific collaboration: part I. The professional origins of scientific co-authorship. Scientometrics 1(1): 65-84.

Beaver, Donald and R. Rosen. 1979a. Studies in scientific collaboration: part II. Scientific co-authorship, research productivity and visibility in the French scientific elite, 1799-1830. Scientometrics 1(2): 133-49.

Beaver, Donald and R. Rosen. 1979b. Studies in scientific collaboration: part III. Professionalization and the natural history of modern scientific co-authorship.

Scientometrics 1(3): 231-45.

Ben-David, Joseph. 1991. Scientific Growth: Essays on the Social Organization and Ethos of Science. Oxford, England: University of California Press.

Biderman, Albert D. and E.T. Crawford. 1970. Paper-money: trends of research sponsorship in American sociology journals. Social Science Information/Information sur les sciences sociales 9(1): 51-77.

Bulmer, Martin. 1981. Quantification and Chicago social science in the 1920s: a negleted tradition. Journal of the History of the Behavioral Sciences 17: 312-31.

Camic, Charles and Yu Xie. 1994. The statistical turn in American social science: Columbia university, 1890 to 1915. American Sociological Review 59(6): 773-805.

Chapoulie, Jean-Michel. 1991. La seconde fondation de la sociologie française, les EtatsUnis et la classe ouvrière. Revue Française de Sociologie 32(3): 321-61.

Chenu, Alain. 1998. La non-professionnalisation de la sociologie française. Les sociologues, l'université de masse et le marché de l'emploi. Unpublished paper, presented at the international conference of the ISA. Montréal: 26 july-1 august.

Chubin, Daryl E. 1975. The journal as a primary data source in the sociology of science: with some observations from sociology. Social Science Information/Information sur les sciences sociales 14(1): 157-68.

Clark, Terry N. 1998. Clientelism and universalism: Columbia sociology under Merton and Lazarsfeld. In Paul Lazarsfeld 1901-1976. La sociologie de Vienne à New York, edited by B.P. Lecuyer and J. Lautman, Paris: L'Harmathan.

Dear, Peter, ed. 1991. The literary structure of scientific arguments. Philadelphia: University of Pennsylvania Press.

Drouard, Alain. 1982. Réflexions sur une chronologie: le développement des sciences sociales en France de 1945 à la fin des années soixante. Revue Française de Sociologie 23(1): 55-85.

Edge, David. 1979. Quantitative measures of communication in science: a critical review. History of Science 17: 102-34.

Endersby, James W. 1996. Collaborative research in the social sciences: multiple authorship and publication credit. Social Science Quarterly 77(2): 375-92.

Farrugia, Francis. 1999. Généalogie d'une professionnalisation: la sociologie française de 1945 à 1960. L'Homme et la Société 131: 23-42.

Gerson, Elihu M. 1983. Scientific work and social worlds. Knowledge: Creation, Diffusion, Utilization, 4(3): 357-377. 
Glenn, Norval D. 1971. American sociologists' evaluation of sixty-three journals. American Sociologist 6(4): 298-303.

Hargens, Lowell. 1991. Impressions and misimpressions abouts sociology journals. Contemporary Sociology 20: 343-9.

Heffner, Alan G. 1981. Funded research, mutiple authorship, and subauthorship collaboration in four disciplines. Scientometrics 3(1): 5-12.

Jenkins, William I. and Irving Velody. 1970. The social sciences and government: do the natural sciences show the prescribed path ? Social Science Information/Information sur les sciences sociales 9(5): 91-118.

Katz, J. Sylvan and Ben R. Martin. 1997. What is research collaboration ? Research Policy 26(1): 1-18.

Lepenies, Wolf. 1988. Between literature and science: The rise of sociology. Cambridge: Cambridge University Press.

McCartney, J.L. 1970. On being scientific: changing styles of presentation of sociological research. American Sociologist 5(1): 30-5.

McCartney, J.L. 1971. The financing of sociologcal research: trends and consequences. In The Phenomenon of Sociology, edited by E. A. Tiryakian, 384-97. New York: AppletonCentury-Crofts.

Mendras, Henry. 1995. Comment devenir sociologue. Souvenirs d'un vieux mandarin. Paris: Actes Sud.

Mucchielli, Laurent. 1998. La Découverte du social: naissance de la sociologie en France (1870-1914). Paris: La Découverte.

Oromaner, M. 1974. The impact of sponsored and non-sponsored publication in sociology. American Sociologist 9(1): 36-9.

Oromaner, M. 1975. Collaboration and impact: the career of multi-authored publications. Social Science Information/Information sur les sciences sociales 14(1): 147-55.

Patel, Narsi. 1972. Quantitative and collaborative trends in American sociological research. American Sociologist 7(1): 5-6.

Patel, Narsi. 1973. Collaboration in the professionnal growth of American sociology. Social Science Information/Information sur les sciences sociales 12(6): 77-92.

Perrucci, Robert, Kathleen O'Flaherty, and Harvey Marshall. 1983. Market conditions, productivity and promotion among university faculty. Research in Higher Education 19: 431-49.

Piriou, Odile. 1999. La sociologie: métier ou profession ? Quand les sociologues prennent position sur l'exercice de la sociologie. L'Homme et la Société 131: 43-64.

Pollak, Michael. 1976. La planification des sciences sociales. Actes de la Recherche en Sciences Sociales 2-3: 105-21.

Pollak, Michael. 1979. Paul F. Lazarsfeld, fondateur d'une multinationale scientifique. Actes de la Recherche en Sciences Sociales 25: 45-59.

Pontille, David. 2000a. Figures de la signature scientifique. Cahiers Internationaux de Sociologie 109: 283-316.

Pontille, David. 2000b. La Signature scientifique: espaces d'inscription et mises en ordre. Thesis, département de sociologie, Université Toulouse II, Toulouse.

Price, Derek J. 1963. Little science, big science. New York: Columbia University Press.

Ross, Dorothy. 1991. The origins of American social science. Cambridge: Cambridge University Press. 
Sainsaulieu, Renaud. 1988. La profession de sociologue en France. In Les champs de la sociologie française, edited by H. Mendras and M. Verret, 247-56. Paris: Armand-Colin.

Shanas, E. 1945. The American Journal of Sociology through fifty years. American Journal of Sociology 50: 522-33.

Simpson, Richard L. 1961. Expanding and declining fields in American sociology. American Sociological Review 26(3): 458-66.

Strauss, A. 1982. Social worlds and legitimation processes. In Studies in Symbolic Interaction, edited by N. Denzin, 171-190. London et Greenwich: JAI Press

Turner, S. P. and J. H. Turner. 1990. The impossible science: an institutional analysis of American sociology: Sage Library of Social Research.

Wanderer, Jules J. 1966. Academic origins of contributors to the American Sociological Review. American Sociologist 1(5): 241-3.

Wieviorka, Michel. 1996. Postface : La sociologie sous tension. Cahiers Internationaux de Sociologie 101: 319-32.

Wiley, Norbert. 1979. Recent journal sociology: the substitution of method for theory. Contemporary Sociology 8: 793-9.

Wilner, Patricia. 1985. The main drift of sociology between 1936 and 1982. History of Sociology 5(2): 1-20.

Wolfe, Alan. 1990. Books vs. articles: two ways of publishing sociology. Sociological Forum 5(3): 466-89.

Yoels, William C. 1971. Destiny or dynasty: doctoral origins and appointment patterns of editors of the American Sociological Review. American Sociologist 6(2): 134-9.

Yoels, William C. 1974. The structure of fields and the allocation of editorships on scientific journals: some observations on the politics of knowledge. Sociological Quarterly 15: 264-76.

Zuckerman, Harriet A. 1965. Nobel laureates: sociological studies of scientific collaboration.

Ph.D. dissertation Thesis, department of sociology, Columbia University, New York. 